\title{
Audiological abnormalities in the Klippel-Feil syndrome
}

\author{
J M McGaughran, P Kuna, V Das
}

\begin{abstract}
Klippel-Feil syndrome (KFS) is defined as a short neck with decreased movement and low posterior hairline. Radiologically, there is a failure of cervical segmentation. Deafness is a well known associated feature and may be of sensorineural, conductive, or mixed type. The audiological assessment of 44 patients with KFS is reported. Thirty five were found to have abnormalities on audiological testing. The presence of other features in these patients, reviews of data from other reports, and the need for further study are discussed.

(Arch Dis Child 1998;79:352-355)
\end{abstract}

Keywords: audiological abnormalities; Klippel-Feil syndrome

In 1912, Maurice Klippel and Andre Feil ${ }^{1}$ described a 46 year old tailor with "fused" cervical vertebrae. He had the classic clinical triad found in the condition now known as KlippelFeil syndrome (KFS); short neck, low posterior hairline (fig 1), and reduced neck movement. Radiologically, there is apparent fusion of the cervical vertebrae (fig 2). The incidence of KFS is 1 in $40000^{2}$ and it can be divided into three types depending on the extent of vertebral involvement ${ }^{3}$ (table 1 ).

The incidence and inheritance of the condition varies with the type of KFS. The incidence of associated anomalies, including Sprengel

Department of Clinical Genetics, St Mary's Hospital, Manchester, UK

J M McGaughran

\section{Hearing Assessment} Centre, Timperley Health Centre, Trafford Health Care NHS Trust, Timperley, UK

P Kuna

\section{University}

Department of Audiological Medicine, Manchester Royal Infirmary, Manchester, UK

V Das

Correspondence to: Dr McGaughran, Department of Clinical Genetics, St Mary's Hospital Hathersage Road, Manchester M13 0JH, UK.

Accepted 28 April 1998 shoulder, cleft palate, cardiac and renal anoma-

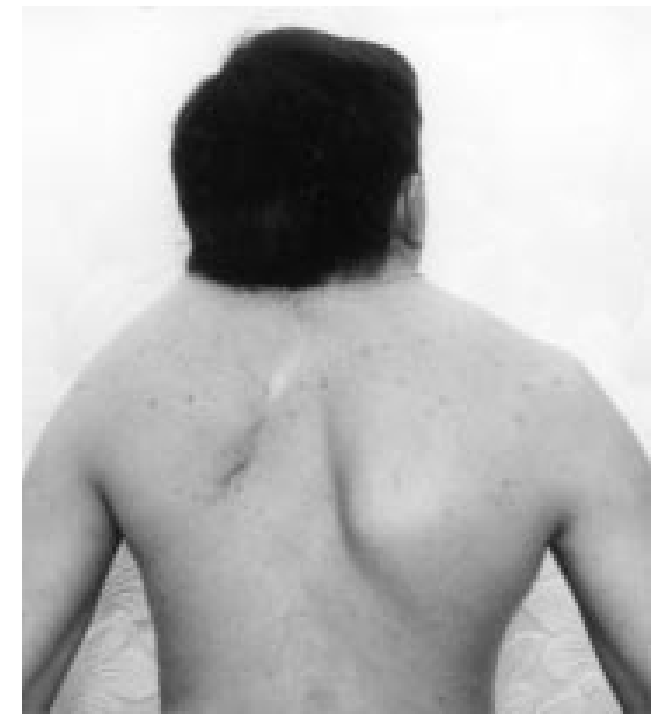

Figure 1 A patient with Klippel-Feil syndrome. A low posterior hairline and short neck are characteristic of the condition.
Table 1 Clinical features of Klippel-Feil syndrome

\begin{tabular}{ll}
\hline KFS type & Features \\
\hline 1 & $\begin{array}{l}\text { Massive cervical fusion, may involve upper } \\
\text { thoracic vertebrae }\end{array}$ \\
2 & $\begin{array}{l}\text { Fusion at } 1 \text { or } 2 \text { interspaces, may be associated } \\
\text { with other vertebral anomalies-for example, } \\
\text { hemivertebrae }\end{array}$ \\
3 & Fusion of cervical and lower thoracic vertebrae
\end{tabular}

lies, and developmental delay, also appears to vary with KFS type. Girls appear to be affected more frequently by the more severe types 1 and 3 but there is an equal sex incidence in type 2 . The cause of the condition is probably heterogeneous with both a genetic and environmental aetiology being cited. The insult occurs between the third and fourth week of embryonic development, causing faulty segmentation of the mesodermal somites. It is this aberrant segmentation rather than fusion which produces the abnormality.

Although the original case was not said to have hearing loss, subsequent studies have shown a significant association between all three types of KFS and deafness. ${ }^{4-8}$ The original report of hearing deficits was by Jalladeau in 1936 who described 20 patients of which $30 \%$ were deaf. ${ }^{9}$ In 1974 , Hensinger et al found $36 \%$ of patients in their study had hearing loss. ${ }^{10} \mathrm{~A}$ review by Helmi and Pruzansky in 1980 suggested hearing impairment was present in $24 \%$ of KFS patients, although in

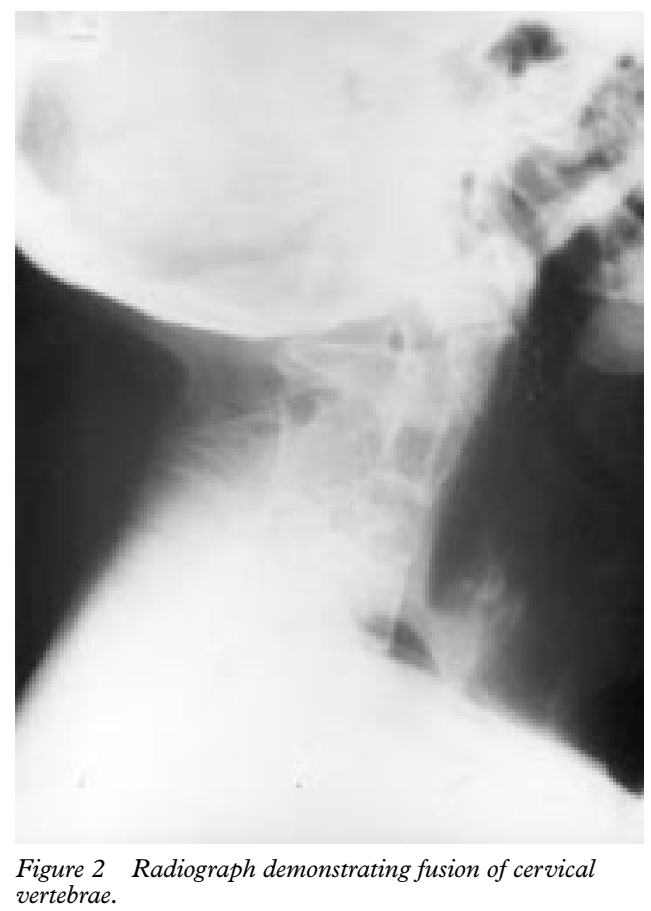


Table 2 Defintions of hearing loss

\begin{tabular}{ll}
\hline Mild & $<40 \mathrm{dBHL}$ \\
Mild-moderate & $40-70 \mathrm{dBHL}$ \\
Moderate-severe & $71-90 \mathrm{dBHL}$ \\
Severe-profound & $>90 \mathrm{dBHL}$ \\
\hline
\end{tabular}

their own seven cases, five patients had some degree of hearing loss. ${ }^{11}$ Radiological imaging, ${ }^{12}$ surgical exploration, ${ }^{13}$ and postmortem examination ${ }^{14}$ have all helped to delineate the cause of the hearing problems in KFS. The pathological processes and hence the type of deafness observed have been varied. Despite the association between KFS and deafness being well recognised, most information is from single case reports or reports of only a few cases. There has been no systematic study assessing the hearing of a large number of patients with KFS.

One of us (JMcG) undertook a clinical and genetic study of KFS. During the course of this study it became apparent that a significant cause of morbidity was a hearing deficit. A formal audiological assessment of patients with KFS was undertaken to establish further the nature of the abnormalities.

\section{Methods}

Patients from the study who were living in the North West and Mersey regions of the UK were contacted and offered audiological assessments in the university department, at the Hearing Assessment Centre, Timperley or at a home visit. Audiological data previously obtained were used from eight patients outside these regions and five patients in the regions who had declined further testing. Consent was obtained at the beginning of the study. A detailed history was taken and clinical examination and audiological assessment performed.

Forty three patients were contacted. Five declined to be tested and, of these, three had no reported problem; two did have hearing problems and previous audiological data were obtained. No reply was received from seven patients, four of whom reported no problem. The remaining three had reported problems and their audiological data obtained from case notes were assessed (consent to access these case notes was obtained as part of the original study).

Audiological assessment included clinical examination and otoscopy. Pure tone audiometry was undertaken, including bone conduction testing with masking and impedance testing. The degree of hearing loss was classified using the average of hearing thresholds at 0.5, 1,2 and $4 \mathrm{kHz}$ frequencies according to the criteria listed in table 2 . Where there was a discrepancy in the degree of hearing loss between the two sides, patients were placed into the category reflecting the most severe loss.

KFS patients had been seen as part of a study to define further the associated range of anomalies and to undertake chromosome and genetic tests to look for possible aetiologies. Full personal and family histories were taken in all cases and the patients were examined. The
Table 3 Distribution of cases according to age and sex

\begin{tabular}{lccc}
\hline Age (years) & Male & Female & Total \\
\hline Under 5 & 1 & 3 & 4 \\
$6-10$ & 4 & 5 & 9 \\
$11-20$ & 6 & 6 & 12 \\
$21-30$ & 3 & 2 & 5 \\
$31-40$ & 2 & 10 & 12 \\
$41-50$ & 0 & 0 & 0 \\
51 and over & 2 & 0 & 2 \\
Total & 18 & 26 & 44 \\
\hline
\end{tabular}

Table 4 Type of hearing loss related to Klippel-Feil type

\begin{tabular}{lccll}
\hline $\begin{array}{l}\text { Type of hearing } \\
\text { loss }\end{array}$ & Type 1 & Type 2 & Type 3 & $\begin{array}{l}\text { Type } \\
\text { unknown }\end{array}$ \\
\hline None & 4 & 3 & 2 & \\
Sensorineural & 8 & 5 & 2 & \\
Conductive & 5 & 1 & 0 & 1 \\
Mixed & 5 & 3 & 2 & \\
Not known & 2 & 1 & 0 & \\
Total & 24 & 13 & 6 & 1 \\
\hline
\end{tabular}

patients were ascertained through patient support groups, other consultants in the region, and colleagues from around the country. Over 60 patients were seen as part of the larger study of whom 44 were included in our study. Thirty one patients were audiologically assessed by us and data obtained at other centres analysed for 13 patients. Data from other centres were sometimes limited, coming from general practitioner notes or letters, and the degree and nature of the loss was not clearly stated. Where the data were not accurate enough to categorise fully but described a hearing loss, KFS was described as "type unknown". All but two of the patients had chromosome analysis undertaken. These were all normal. The patients had features of no other separate genetic conditions or syndromes which are associated with deafness. Some did have features of the first/second arch syndrome but as these are considered as part of the anomalies which may be present in KFS, they were not considered separately. In the patient group from outside the region where other data were used, numbers were smaller and the reasons for ascertainment are not known.

\section{Results}

SEX AND AGE DISTRIBUTION OF PATIENTS STUDIED

The well known female preponderance of cases was reflected in the study patients. Twenty six were female and 18 male. The numbers of patients in different age groups is summarised in table 3.

TYPE OF HEARING LOSS

Out of the 44 cases studied, 35 showed hearing loss (20 female, 15 male) while the remaining nine cases had no evidence of any deficit.

Sensorineural hearing loss was the most common, being found in 15 cases. Mixed hearing loss was found in 10 cases and conductive loss in seven cases. In cases where there was a conductive loss, the audiology findings had been confirmed on different occasions, suggesting that the loss was neither acute nor infective in nature, nor related to ongoing or intermittent episodes of secretory otitis media. 
Table 5 Degree of hearing loss related to sex and Klippel-Feil type

\begin{tabular}{|c|c|c|c|c|c|c|c|}
\hline \multirow{2}{*}{$\begin{array}{l}\text { Degree of } \\
\text { hearing loss }\end{array}$} & \multicolumn{2}{|c|}{ Type 1} & \multicolumn{2}{|c|}{ Type 2} & \multicolumn{2}{|c|}{ Type 3} & \multirow[b]{2}{*}{ Total } \\
\hline & Male & Female & Male & Female & Male & Female & \\
\hline None & 3 & 1 & 0 & 3 & 0 & 2 & 9 \\
\hline Mild & 2 & 3 & 2 & 1 & 0 & 1 & 9 \\
\hline Mild-moderate & 1 & 2 & 0 & 0 & 0 & 0 & 3 \\
\hline Moderate-severe & 3 & 2 & 2 & 1 & 0 & 1 & 9 \\
\hline Severe-profound & 1 & 3 & 1 & 2 & 0 & 2 & 9 \\
\hline Not known & 1 & 2 & 1 & 0 & 0 & 0 & 4 \\
\hline Total & 11 & 13 & 6 & 7 & 0 & 6 & 43 \\
\hline
\end{tabular}

There was insufficient information to comment on the nature of the loss in three cases.

DISTRIBUTION AND DEGREE OF HEARING LOSS IN RELATION TO KFS TYPE.

It was possible to assign 43 of the patients to one of the three KFS types. Insufficient data were available for the other patient. The type of hearing loss related to the KFS type is shown in table 4 . Type $1 \mathrm{KFS}$ was present in 24 cases tested and $83 \%$ of these had some abnormality on testing. Type $2 \mathrm{KFS}$ was found in 13 patients with $77 \%$ of these having some abnormality. There were six cases with type 3 KFS and $66 \%$ of these had an abnormal test result. For both male and female patients, the most common type associated with hearing impairment is type 1 , followed by type 2 . The least common was type 3 , of which there were only six female cases. Table 5 shows the distribution and degree of hearing loss related to both KFS type and the sex of the patient.

RELATION TO OTHER CLINICAL FEATURES

The hearing loss was also related to the clinical features of the patients. In some cases there may have been other factors in the aetiology of the deafness. Six patients had a cleft palate (a well recognised anomaly associated with KFS) and one had had neonatal meningitis. However, in most cases no factors except KFS were present. In other cases a cause for deafness could be found which is likely to be directly related to KFS. One child had an ossicular chain anomaly which is well described with KFS. Another had cochlear agenesis which has not been described before although similar abnormalities have been found. ${ }^{13}$

\section{Discussion}

KFS is clinically characterised by a short, usually immobile, neck. A number of possible aetiological factors have been suggested which may be contributory in different patients. ${ }^{15-19} \mathrm{It}$ is believed to be caused by faulty segmentation of the mesodermal somites. Although usually sporadic, some cases are autosomal dominant. ${ }^{20}$ There is a well recognised female preponderance, with a female to male ratio estimated by Helmi and Pruzansky to be $1.3: 1{ }^{11}$ In this study it is slightly higher at 1.5:1. A number of other anomalies are associated with KFS including cardiac and renal anomalies, developmental delay, and limb defects. Scoliosis is a frequent finding, seen in up to $60 \%$. $^{102122}$

Audiological abnormalities are also common although detailed information about these is very limited. Some authors have reported the association with hearing loss to be up to $50 \%$. In this study, we set out to determine in a systematic way the frequency and extent of abnormalities in these patients. Eighty per cent of the cases were found to be associated with a degree of hearing loss although in some this was only mild or unilateral.

All types of hearing problems have been described in the syndrome but bilateral sensorineural loss is most common. In this study, $43 \%$ with hearing loss were found to have sensorineural loss. The next most common problem is mixed hearing loss followed by conductive hearing loss. Although many authors have reported the association of KFS and hearing loss, no characteristic profile of audiograms has been reported. Similarly, in the present study, there was no particular characteristic, shape, or profile identified in the audiograms.

Several otological abnormalities have been noted with these patients ranging from nonspecific external ear abnormalities to severe developmental anomalies of the cochlea. ${ }^{23} 24$ External ear anomalies include narrow external auditory meati, preauricular skin tags, and small ears. The inner ear changes include absent vestibules and semicircular canals. ${ }^{25}$ Cochlear abnormalities include total absence of the cochlea, decreased number of coils, and a Mondini anomaly. ${ }^{26}$ Various abnormalities of the ossicular chain are also described. These include deformed or absent ossicles, malformed or fixed stapes, and fusion of components of the ossicular chain. ${ }^{27}{ }^{28}$ In some cases, non-specific hyperostotic changes of the entire footplate have been recorded. ${ }^{29}$

In this study, the most common type of KFS seen was type 1 . This may be caused by biased ascertainment as these patients are more likely to come to medical attention. It may be that type 2 is more common in the population, particularly as the mode of inheritance may be autosomal dominant, but patients with this type may have minimal clinical manifestations and only be diagnosed at radiography. Twenty of the 24 type 1 cases had some degree of hearing loss. The prevalence of hearing loss in this group may reflect the nature of the embryonic insult which produces abnormalities in the development of both the cervical spine and the ear. This is, however, not always consistent as the child with a known ossicular chain anomaly and the child with cochlear agenesis both had type 2 KFS.

The KFS anomaly may also be found in Wildervanck syndrome, ${ }^{30}$ which is specifically associated with deafness. This condition comprises the KFS anomaly, Duane syndrome (lateral rectus palsy with retraction of the globe of the affected eye on abduction), and hearing loss. Mental retardation may also be associated with the condition which usually affects female patients although affected male patients have been described. ${ }^{31}$ Three female patients had Wildervanck syndrome although there was a pronounced variation in the degree of hearing loss they had.

Two patients had the MURCS (mullerian duct anomalies, renal agenesis and cervical 
somite dysplasia) association. One of the patients had features which might also be considered in the VATER ${ }^{32}$ (vertebral anomalies, anal atresia, tracheo-oesophageal fistula, and radial ray defects) association. It has been suggested that the common aetiology for these conditions may be a disruption of the normal mesodermal development. ${ }^{33}$ The same explanation has also been given for the first/second arch syndrome of which some of the patients had features. ${ }^{34}$

A number of issues has emerged from this study. Audiological abnormalities are present in a significant number of patients with KFS. In the group of patients studied here, $80 \%$ had some degree of impairment. Establishing the degree and type of hearing loss should be an integral part of the management of patients with KFS. Follow up with repeat audiological assessment should also be considered, as a conductive loss associated with, for example, hyperostotic changes at the footend of the stapes may become clinically significant in later life if associated with chronic low grade inflammation.

Patients with KFS may attend clinics in a number of specialties, including orthopaedic, cardiac, renal, or neurological clinics. It is important for others involved in their care to be aware of the strong association with hearing problems and ensure formal audiological testing is undertaken. Although some have investigated cases further with radiological imaging ${ }^{26}$ most cases have not been extensively investigated. Some cases with profound hearing impairment need further assessment to ascertain the feasibility of cochlear implantation or whether other modes of auditory rehabilitation such as surgical intervention ${ }^{27}$ can be undertaken.

This study has clearly shown that a large proportion of patients with KFS have hearing impairment. Vestibular abnormalities were not assessed and further evaluation of these functions in KFS patients would be important.

We wish to thank our colleagues for referring patients for the KFS study, to the patient support groups, and the patients themselves for taking part in the study.

1 Klippel M, Feil A. Un cas des vertebres cervicales avec cage thoracique remontent justu'a la base du crane. Novelle Iconographic de las Saltpetriere 1912;25:223-50.

2 Gorlin RJ, Cohen MM, Levin SL. Klippel-Feil anomaly. In: Gorlin RJ, Cohen MM, Levin SL, eds. Syndromes of the hoad and neck. New York: Oxford University Press, 1990: head and 886 .

3 Feil A. L'absence et la diminution des vertebres cervicales (etude clinique et pathologique): le syndrome de reduction numerique cervicale. Thesis de Paris, 1919.
4 McLay K, Maran AGD. Deafness and the Klippel-Feil syndrome. F Laryngol 1969;83:175-84.

5 Singh SP, Rock EH, Shulman A. Klippel-Feil syndrome with unexplained apparent conductive hearing loss: a case report. Laryngoscope 1969;79:113-7.

6 Palant DI, Carter BL. Klippel-Feil syndrome and deafness. Am 7 Dis Child 1972;123:218-21.

7 Stark EW, Borton TE. Hearing loss and the Klippel-Feil syndrome. Am f Dis Child 1972;123:233-5.

8 Stark EW, Borton TE. Klippel-Feil syndrome and associated hearing loss. Arch Otolaryngol 1973;97:415-9.

9 Jalladeau J. Malformations congenitales associees au syndrome de Klippel-Feil. Thesis de Paris, 1936.

10 Hensinger RN, Lang JE, MacEwen GD. Klippel-Feil syndrome: a constellation of associated anomalies. F Bone foint Surg 1974;56:1246-53.

11 Helmi C, Pruzansky S. Craniofacial and extracranial malformations in the Klippel-Feil syndrome. Cleft Palate fournal 1980;17:65-81.

12 Everberg G, Ratjen E, Sorensen H. Wildervanck's syndrome: Klippel-Feil syndrome associated with deafness and retraction of the eyeball. Br f Radiol 1963;36:562-7.

13 Everberg G. Congenital absence of the oval window. Acta Otolaryngol (Stockh) 1968;66:495-504.

14 Sakai M, Hirosater M, Shiikawa A, Komatsu N. Klippel-Feil syndrome with conductive deafness and histological findings of removed stapes. Ann Otol Rhinol Laryngol 1983; 92:202-5

15 Erskine CA. An analysis of Klippel-Feil syndrome. Arch Pathol 1946;41:269-81

16 Gardner WJ, Collis JS. Klippel-Feil syndrome. Arch Surg 1961;83:638-44.

17 Gray S, Romaine CB, Skandalaki SJ. Congenital fusion of the cervical vertebrae. Collective review. Surg Gynaecol Obstet 1964;118:373-85.

18 Neidengard L, Carter TE, Smith DW . Klippel-Feil malformation complex in fetal alcohol syndrome. Am $\mathcal{f}$ Dis Child 1978;102:929-30.

19 Shoul MJ, Ritvo M. Clinical and roentgenological manifestation of Klippel-Feil syndrome. Am $\mathcal{F}$ Roentgen Rad Ther 1952;68:369-85.

20 Gunderson CH, Greenspan RH, Glaser GH, Lubs HA. The Klippel-Feil syndrome: genetics and clinical re-evaluation of cervical fusion. Medicine 1967;46:491-512.

21 Jarvis JF, Sellars SL. Klippel-Feil deformity associated with congenital conductive deafness. F Laryngol Otol 1974;88: $285-9$.

22 Nora JJ. Klippel-Feil syndrome with congenital heart disease. Am J Dis Child 1961;102:858-64.

23 Baumeister S, Terrahe K. Malformation of the inner ear in Klippel-Feil syndrome. Laryngol Rhinol Otol 1974;53:121 30.

24 Miyamoto RT, Yune HY, Rosevear WH. Klippel-Feil syndrome and associated ear deformities. Am 7 Otolaryngol 983;5:113-19.

25 Ohtani I, Northrop Dubois C. Aural abnormalities in Klippel-Feil syndrome. Am f Otolaryngol 1985;6:468-71.

26 Windle-Taylor P, Emery PJ, Phelps PD. Ear deformities associated with the Klippel-Feil syndrome. Ann Otolaryngol 1981;90:210-6.

27 Stewart EJ, O'Reilly BF. Klippel-Feil syndrome and conductive deafness. F Laryngol Otol 1989;103:947-9.

28 Daniilidis J, Maganaris T, Dimitriades A. Stapes gusher and Klippel-Feil syndrome. Laryngoscope 1978;88:1178-83.

29 Siliquini PL, Cacaci F. A case of Klippel-Feil syndrome with associated abnormality of the middle ear. Minerva Ortop $1967 ; 18: 734-7$.

30 Wildervanck LS. Een cervico-oculo-acousticus syndroom. Ned Tijdschr Geneeskd 1960;104:2600-5.

31 West PDB, Gholkar A, Ramsden RT. Wildervanck syndrome-unilateral Mondini dysplasia identified by computer tomography. F Laryngol Otol 1989;103:408-11.

32 Quan L, Smith DW. The VATER association. Vertebral defects, anal atresia, T-E fistula with esophageal atresia, radial and renal dysplasia: a spectrum of associated defects. 7 Paediatr 1973;82:104-7.

33 Russell LJ, Weaver DD, Bull MJ . The axial mesodermal dysplasia spectrum. Pediatrics 1981;67:176-82.

34 Duncan PA, Shapiro LR. Interrelationships of the hemifacial microsomia-VATER, VATER and sirenomelia phenotypes. Am $\mathcal{F}$ Med Genet 1993;47:75-84. 